\title{
Article \\ Genetic Analysis of Yield and Quality Characteristics in Provitamin A Hybrid Cassava Families in Ghana
}

\author{
Bright Boakye Peprah ${ }^{1,2}$, Elizabeth Yaa Parkes ${ }^{3}$, Peter Kulakow ${ }^{3}{ }^{\circ}$, Angeline van Biljon ${ }^{2}(\mathbb{D}$ \\ and Maryke Tine Labuschagne ${ }^{2, * \text { (D) }}$ \\ 1 Council for Scientific and Industrial Research, Crops Research Institute, Kumasi 03220, Ghana; \\ brightpeprah@yahoo.com \\ 2 Department of Plant Sciences, University of the Free State, Bloemfontein 9301, South Africa; \\ avbiljon@ufs.ac.za \\ 3 International Institute of Tropical Agriculture, Ibadan 200001, Nigeria; e.parkes@cgiar.org (E.Y.P.); \\ p.kulakow@cgiar.org (P.K.) \\ * Correspondence: labuscm@ufs.ac.za
}

Citation: Boakye Peprah, B.;

Parkes, E.Y.; Kulakow, P.;

van Biljon, A.; Labuschagne, M.T.

Genetic Analysis of Yield and Quality

Characteristics in Provitamin A

Hybrid Cassava Families in Ghana.

Agronomy 2021, 11, 1911. https://

doi.org/10.3390/agronomy11101911

Academic Editor: Matthew Hegarty

Received: 17 August 2021

Accepted: 20 September 2021

Published: 23 September 2021

Publisher's Note: MDPI stays neutral with regard to jurisdictional claims in published maps and institutional affiliations.

Copyright: (c) 2021 by the authors. Licensee MDPI, Basel, Switzerland. This article is an open access article distributed under the terms and conditions of the Creative Commons Attribution (CC BY) license (https:/ / creativecommons.org/licenses/by/ $4.0 /)$.

\begin{abstract}
Cassava is the most widely cultivated and consumed crop in Ghana. Malnutrition is endemic in cassava-producing regions of Africa, partly due to the low micronutrient content of this crop. The aim of this study was to generate genetic information on characteristics such as total carotenoid content, dry matter content, root weight and number, and cassava mosaic disease (CMD), and their possible combination in cassava clones, using a North Carolina II breeding scheme. Five genetically diverse yellow-fleshed clones at advanced selection stages, with CMD resistance, were used as females and two high dry matter content white-fleshed clones, selected from farmers' fields in Ghana, were used as males. Ten $\mathrm{F}_{1}$ families were generated, and evaluated at two locations in Ghana. General combining ability (GCA) mean squares were larger than specific combining ability (SCA) mean squares for harvest index, CMD, and carotenoid content, indicating additive genetic effects. The positive significant correlations that were observed between pulp color and carotenoid content; carotenoid content and CMD; pulp color and CMD; and pulp color and cortex color, make the screening of large numbers of progenies possible in the cassava breeding program. This could allow breeders to combine carotenoid content and CMD at the early breeding stages through visual assessment of pulp color and CMD symptoms. Large numbers of genotypes can be evaluated and a few can be selected to be quantified for carotenoid content at later stages of the breeding program, to save costs. One of the parents (P6), showed positive GCA effects for carotenoid content, dry matter content, $\mathrm{CMD}$ and storage root weight, hence could be used as a parent to generate clones that combine carotenoid content and dry matter content.
\end{abstract}

Keywords: cassava; dry matter content; carotenoids; genetic effects; root yield

\section{Introduction}

The populations of underdeveloped and developing countries often suffer undernourishment and so-called "hidden hunger" as a result of micronutrient deficiencies. Areas in Africa, including Ghana, where cassava is widely consumed, are characterized by rampant malnutrition because its storage roots are low in nutrients such as provitamin A [1]. It is for this reason that the development of nutrient-dense cassava varieties needs much more attention to eliminate the ramifications of malnutrition among the poor in an inexpensive and sustainable way. Vitamin A deficiency constitutes a major public health problem and affects mainly children and women. Several programs in nutrition security have been initiated, for example HarvestPlus, which is a global alliance involving several research institutions, tasked with the development of micronutrient-dense staple crops under the joint partnership of the International Center for Tropical Agriculture (CIAT) and the International Institute for Tropical Agriculture (IITA) [2,3]. Among its several initiatives 
is the development of biofortified cassava clones with high provitamin A content in the roots. On this score, the national cassava breeding program at the Council for Scientific and Industrial Research-Crops Research Institute (CSIR-CRI) initiated a breeding program with the aim of developing high yielding cultivars with high levels of carotenoid content, dry matter content and disease resistance. Deployment of such cassava varieties could sustainably improve nutrition and reduce prevalence of vitamin A deficiency in communities that heavily depend on cassava, especially in the rural population $[4,5]$. Adoption of biofortified cassava genotypes in Ghana will largely depend on their agronomic performance, including storage of fresh roots, dry matter content, resistance to major pests and diseases and the stability of these characteristics over time and space [6]. Dry matter content influences texture after boiling and is also a key parameter in the production of gari (a popular cassava product consumed in Ghana). The strong negative correlation that has been reported between dry matter content and carotenoid content in African cassava germplasm $[5,7,8]$ could present a potential challenge for the breeding programs that are aiming to improve both characteristics. Yet, previous studies $[9,10]$ found that correlations between carotenoid content and dry matter content were not statistically significant when analyzing Latin American cassava germplasm.

\section{Materials and Methods}

\subsection{Crossing Blocks}

The crossing block for this study was first planted in May 2015, at the CSIR-CRI in the semi-deciduous forest zone of Ghana located at $1^{\circ} 30^{\prime} 0^{\prime \prime} \mathrm{W}$ and $6^{\circ} 42^{\prime} 0^{\prime \prime} \mathrm{N}, 186 \mathrm{~m}$ above sea level, with a bimodal rainfall distribution, with two rainy seasons and one dry season. A second crossing block was established at the same location in 2016 due to a limited number of botanical seeds collected during the first hybridization. The soil of the experimental area (Fumesua) is Asuansi series, a ferric Acrisol with sandy loam top soil over sandy clay.

\subsection{Progeny Development}

Seven genetically diverse clones (five yellow-fleshed cassava clones at advanced selection stages by IITA, and two white-fleshed clones selected from farmers' fields in Ghana) were used as progenitors (Table 1).

Table 1. List of progenitors used in the study.

\begin{tabular}{ccccc}
\hline Genotype & Code & Source & RFC & Salient Traits \\
\hline Debor & P1 & Farmer & White & High DMC \\
Wenchi Alata & P2 & Farmer & White & High DMC \\
IBA061635 & P3 & IITA & Light yellow & CMD resistance, pVAC \\
IBA070539 & P4 & IITA & Yellow & CMD resistance, pVAC \\
IBA070593 & P5 & IITA & Yellow & CMD resistance, pVAC \\
IBA090090 & P6 & IITA & Yellow & CMD resistance, pVAC \\
IBA070536 & P7 & IITA & Light yellow & CMD resistance, pVAC \\
\hline
\end{tabular}

IITA, International Institute of Tropical Agriculture; RFC, root flesh color; DMC, dry matter content; CMD, cassava mosaic disease; pVAC, high levels of provitamin A carotenoids.

They were planted in the crossing block at Fumesua under rain fed conditions. Planting was carried out using disease-free stakes planted in three row plots of five plants per row with a plot size of $15 \mathrm{~m}^{2}$. Spacing between and within rows was $1.5 \mathrm{~m}$. Weeding was carried out when necessary. Controlled pollinations were carried out by hand [11]. A North Carolina II design was used to produce $10 \mathrm{~F}_{1}$ families without reciprocals. The seed viability was tested by the floatation method [12]. Non-viable seeds were discarded. At least 110 seeds from each cross were germinated in seed trays in the screen house at the Fumesua station in 2017. 


\subsection{Seedling Nursery Evaluation}

Seedlings from the $10 \mathrm{~F}_{1}$ families were transplanted to the seedling nursery at the Fumesa station in the minor rainy season of August 2017 to generate planting materials for clonal evaluation. The seedlings were established in single rows at $50 \mathrm{~cm}$ by $1 \mathrm{~m}$ spacing between and within rows, respectively. Data were collected from each individual stand per family for severity ratings of CMD taken at 1, 3 and 6 months after planting (MAP) [11]. The seedlings (progenies) were evaluated alongside the progenitors. At harvest (10 MAP), root cortex and pulp color for individual stands were scored based on a standard color chart [11]. Individuals were selected based on the ability to produce enough $(\geq 12)$ standard-size cuttings of about $25 \mathrm{~cm}$ (4-6 nodes).

\subsection{Clonal Evaluation Trial}

Selected individuals were planted in a randomized complete block design (RCBD) with two replications at two sites: Fumesua and Ejisu. The soils for the trial sites were Asuasi series; a ferric acrisol with sandy loam topsoil over sandy clay at Fumesua, and Amantin series; chronic lixisol with sandy loam topsoil at Ejura. Annual rainfall for the sites during the trial period was $1205 \mathrm{~mm}$ at Fumesua and $1311 \mathrm{~mm}$ at Ejura. Each individual was represented by a single row plot of three plants per replication with $2 \mathrm{~m}$ alleys between blocks. Planting was carried out at a spacing of $1 \mathrm{~m} \times 1 \mathrm{~m}$ between and within rows. The clonal trials were planted in July 2018 and harvested in June 2019 for root measurements. Progenies were evaluated alongside the progenitors in the clonal trials. Weeding was carried out when necessary and trials were rain-fed.

\subsection{Agronomic and Morphological Characteristics Measured}

During the growth period, data were collected on severity of CMD using a scale of $1-5$, where 1 represented no symptoms and 5 severe damage [11]. The scoring was carried out at 1, 3 and $6 \mathrm{MAP}$ for $\mathrm{CMD}$, after which an average score for analysis was determined. Plant vigor was also measured at 3 MAP. At harvest (12 MAP), all plants in a row were uprooted and the biomass bulked to estimate yield components by separately weighing the fresh roots $\left(\mathrm{kg} \mathrm{plot}^{-1}\right)$ and foliage $\left(\mathrm{kg} \mathrm{plant}^{-1}\right)$ using a Salter Brecknell suspended weighing scale calibrated in kilograms. Harvest index was measured as a ratio of fresh root weight to total biomass as: fresh root weight/fresh root weight + total biomass. Fresh root yield was measured as root weight assessed on a minimum of two plants per genotype.

Dry matter content was determined by measuring the weight of the storage roots in water and air [13]. The iCheck analytical kit developed by the BioAnalyt laboratory was used for measuring the carotenoid content (https: / /www.bioanalyt.com/product/icheckcarotene/ accessed 8 June 2020). The extraction was carried out following the procedure previously described [5]. Five gram of cassava root sample was taken from each clone, and ground into a smooth and fine paste using a mortar and pestle. To ease grinding, $20 \mathrm{~mL}$ distilled water was added to the sample. The resulting solution was transferred into $50 \mathrm{~mL}$ calibrated Falcon tubes and shaken thoroughly and $0.4 \mathrm{~mL}$ of the solution injected into the $\mathrm{iEx}{ }^{\mathrm{TM}}$ Carotene vial using the syringe and needle provided with the kit. The vials were left to stand for $5 \mathrm{~min}$, it was then shaken again and allowed to stand until two solution phases were seen. The absorbance of the upper phase in the vial was measured using the iCheck kit (reading).

Carotenoid content $\left(\mu \mathrm{g} \mathrm{g}^{-1}\right)$ was calculated as: $(\mathrm{Vs} / \mathrm{Ws}) \times \mathrm{R}$, where $\mathrm{Vs}$ is the volume and Ws the weight of the measured sample. $R$ is the final reading at $450 \mathrm{~nm}$ wavelength.

\subsection{Statistical Design and Data Analysis}

Analysis of variance (ANOVA) was performed to determine the significance of genetic differences for the characteristics/variables measured in the $2 \times 5$ balanced NCD II experiment, within and across locations. The RCBD model of NCD II was used for the genetic analysis and it considered the effect of location, both male and female parents, their interaction and each interaction with the location and all of their interactions together. 
GCA and SCA effects were estimated based on the parental effects, and their interaction. All the analyses were performed using Analysis of Genetic Design with R for Windows (AGD-R) v5.0 software [14].

Variation due to males, females, and males $\times$ females were denoted as GCAm, GCAf, and SCA variation, respectively. For CMD, GCA and SCA effects should be negative, as the preference is for low values. For all other characteristics, positive estimates of GCA and SCA effects were used to identify genotypes with high yield and yield components. The relative importance of additive (GCA) and non-additive (SCA) genetic effects in explaining the performance of the progeny for each of the characteristics was determined by individually expressing the GCAf mean square, GCAm mean square, and the SCA mean square as a percentage of the treatment (crosses) mean squares $[15,16]$.

\section{Results}

For all genotypes of the $10 \mathrm{~F}_{1}$ families, carotenoid content ranged from 1.20 to $9.10 \mu \mathrm{g} \mathrm{g}^{-1}$, with the highest mean $\left(6.14 \mu \mathrm{g} \mathrm{g}^{-1}\right)$ recorded for family P1 $\times$ P6 and the lowest $\left(2.98 \mu \mathrm{g} \mathrm{g}^{-1}\right)$ for family P1 $\times$ P7 (Table 2 ).

Table 2. Mean performance of progenitors and their $F_{1}$ progenies evaluated across two locations in Ghana.

\begin{tabular}{|c|c|c|c|c|c|c|c|c|}
\hline Parent/Family & No & CMD & DMC & HI & RTN & RTW & TCC & TWT \\
\hline & & & $\%$ & & & $\operatorname{kg~plot}^{-1}$ & $\mu g g^{-1}$ & kg \\
\hline P1 (Debor) & & 2.05 & 35.40 & 0.45 & 28.60 & 15.77 & 0.80 & 20.20 \\
\hline P2 (Wenchi Alata) & & 1.99 & 34.20 & 0.42 & 27.13 & 15.36 & 0.75 & 22.06 \\
\hline P3 (IBA061635) & & 1.57 & 31.66 & 0.46 & 26.75 & 16.77 & 3.53 & 19.22 \\
\hline P4 (IBA070539) & & 1.56 & 31.84 & 0.42 & 29.76 & 16.42 & 5.41 & 22.60 \\
\hline P5 (IBA070593) & & 1.99 & 27.40 & 0.43 & 26.78 & 16.09 & 5.70 & 20.23 \\
\hline P6 (IBA090090) & & 2.05 & 32.27 & 0.45 & 26.69 & 17.15 & 5.33 & 21.84 \\
\hline P7 (IBA070536) & & 1.29 & 27.69 & 0.44 & 29.34 & 17.45 & 3.28 & 22.99 \\
\hline $\mathrm{P} 1 \times \mathrm{P} 3$ & 20 & 1.39 & 36.28 & 0.46 & 26.39 & 15.25 & 3.34 & 18.47 \\
\hline $\mathrm{P} 1 \times \mathrm{P} 4$ & 17 & 1.53 & 27.64 & 0.43 & 30.06 & 15.77 & 5.68 & 21.32 \\
\hline $\mathrm{P} 1 \times \mathrm{P} 5$ & 16 & 1.91 & 27.94 & 0.45 & 29.25 & 16.38 & 5.61 & 20.26 \\
\hline $\mathrm{P} 1 \times \mathrm{P} 6$ & 18 & 1.90 & 32.70 & 0.46 & 27.18 & 18.35 & 6.14 & 21.93 \\
\hline $\mathrm{P} 1 \times \mathrm{P} 7$ & 16 & 1.19 & 27.80 & 0.46 & 30.13 & 18.08 & 2.98 & 21.51 \\
\hline $\mathrm{P} 2 \times \mathrm{P} 3$ & 15 & 1.74 & 27.04 & 0.45 & 27.12 & 16.29 & 3.72 & 19.98 \\
\hline $\mathrm{P} 2 \times \mathrm{P} 4$ & 19 & 1.59 & 36.03 & 0.42 & 29.46 & 17.07 & 5.13 & 23.88 \\
\hline $\mathrm{P} 2 \times \mathrm{P} 5$ & 14 & 2.08 & 26.86 & 0.40 & 24.30 & 14.34 & 5.79 & 20.20 \\
\hline $\mathrm{P} 2 \times \mathrm{P} 6$ & 14 & 2.21 & 32.24 & 0.43 & 26.20 & 15.94 & 4.50 & 21.75 \\
\hline $\mathrm{P} 2 \times \mathrm{P} 7$ & 11 & 1.39 & 27.58 & 0.41 & 28.59 & 16.81 & 3.57 & 24.49 \\
\hline Grand mean & & 1.69 & 30.74 & 0.44 & 27.87 & 16.43 & 4.19 & 21.38 \\
\hline S.e.m. & & 0.07 & 0.83 & 0.005 & 0.40 & 0.25 & 0.40 & 0.39 \\
\hline
\end{tabular}

CMD, Cassava mosaic disease; DMC, Dry matter content; HI, Harvest index; RTN, Storage root number; RTW, Storage root weight; TCC, Total carotenoid content; TWT, Total biomass; s.e.m., standard error of means.

Individual dry matter content values for the evaluated genotypes ranged from $19.70 \%$ to $42.4 \%$. Dry matter content means ranged from $26.86 \%$ for family P2 $\times$ P5 to $36.28 \%$ for family P1 $\times$ P3 . Family P1 $\times$ P6 recorded the highest mean root weight $\left(18.35 \mathrm{~kg} \mathrm{plot}^{-1}\right)$ while family P2 $\times$ P5 recorded the lowest mean root weight $\left(14.34 \mathrm{~kg} \mathrm{plot}^{-1}\right)$. At the parental level, genotypes P1 and P2 recorded the highest value for dry matter content and CMD (35.4\% and 2.05, and $34.20 \%$ and 1.99 , respectively), but they had the lowest levels of carotenoid content and root weight compared to the yellow parental genotypes P4-P7. The GCA mean squares for female progenitors were highly significant for all characteristics measured, except for root number (Table 3). The SCA mean squares for dry matter content, root weight and carotenoid content were also highly significant. The GCA mean squares for the CMD and total biomass for male progenitors were highly significant as well, while the SCA mean squares were not. The GCA effects for both males and females, and SCA effects were significant for RWT and harvest index, indicating both additive and non-additive 
gene effects for these characteristics. The male and female GCA mean squares, as well as SCA mean squares, showed various levels of significance for CMD, harvest index, root number, root weight and total biomass, indicating the importance of both additive and non-additive gene effects.

Table 3. Mean squares of crosses and sum of squares for combining ability effects of seven traits evaluated in $10 \mathrm{~F}_{1}$ families and seven parents across two locations.

\begin{tabular}{ccccccccc}
\hline Source & df & CMD & DMC & HI & RTW & TCC & TWT & RTN \\
\hline Locations & 1 & $0.78^{* * *}$ & 9.56 & 0.01 & $162.41^{* * *}$ & $272.75^{* * *}$ & 45.69 & 62.50 \\
Genotype & 9 & $6.63^{* * *}$ & $963.89^{* * *}$ & $0.03^{* * *}$ & $97.62^{* * *}$ & $87.77^{* * *}$ & $208.88^{* * *}$ & $233.37^{* *}$ \\
Male & 1 & $7.83^{* * *}$ & $10.22^{* * *}$ & $0.15^{* * *}$ & $55.31^{*}$ & 2.26 & $322.89^{* * *}$ & $248.04^{* *}$ \\
Female & 4 & $12.48^{* * *}$ & $798.46^{* * *}$ & $0.02^{* * *}$ & $106.28^{* * *}$ & $173.95^{* * *}$ & $325.61^{* * *}$ & 323.10 \\
SCA & 4 & 0.49 & $1367.74^{* * *}$ & $0.01^{* *}$ & $99.53^{* * *}$ & $25.22^{* * *}$ & 63.64 & $139.975^{* *}$ \\
Error & 618 & 0.28 & 8.28 & 0.01 & 10.89 & 1.05 & 28.99 & 37.30 \\
GCAm & & 13.12 & 0.12 & 50.50 & 6.30 & 0.28 & 17.17 & 15.11 \\
GCAf & & 83.57 & 36.85 & 31.89 & 48.38 & 87.09 & 69.28 & 78.24 \\
SCA & & 3.31 & 63.03 & 17.61 & 45.32 & 12.63 & 13.54 & 6.15 \\
GCA:SCA & & 4.96 & 1.00 & 3.87 & 1.14 & 1.02 & 2.27 & 3.46 \\
Baker ratio & & 0.98 & 0.48 & 0.88 & 0.66 & 0.92 & 0.91 & 0.81 \\
\hline
\end{tabular}

${ }^{*} p \leq 0.05 ;{ }^{* *} p \leq 0.01:{ }^{* *} p \leq 0.001 ; \mathrm{CMD}$, Cassava mosaic disease; DMC, Dry matter content; HI, Harvest index; RTN, Storage root number; RTW, storage root weight; $\overline{T C C}$, Total carotenoid content; TWT, Total biomass.

The GCA sum of squares for female progenitors accounted for more of the total variation than the GCA sum of squares for male progenitors for dry matter content. The SCA sum of squares accounted for $63.03 \%$ of dry matter content cross sum of squares. The GCA:SCA ratio for all the characteristics were higher than 1 except for dry matter content (1.00) where there were higher SCA than GCA effects (Table 3).

\subsection{General Combining Ability Effects}

P2 (Wenchi Alata), a white-fleshed progenitor with negligible carotenoid content, had a negative carotenoid content GCA effect of -0.13 (Table 4). This indicates the unsuitability of this parent as a good combiner when targeting high carotenoid in the progeny.

Table 4. General combining ability effects of cassava progenitors for seven traits at two locations in Ghana.

\begin{tabular}{cccccccc}
\hline Progenitor & CMD & DMC & HI & RTN & RTW & TCC & TWT \\
\hline P1 & -0.10 & -0.17 & 0.01 & 0.69 & 0.31 & 0.08 & -0.58 \\
P2 & 1.68 & -0.61 & -0.02 & -0.78 & $-0.36^{* *}$ & $-0.13^{*}$ & 0.78 \\
P3 & -0.11 & 1.09 & $0.02 *$ & -1.16 & -0.68 & -1.14 & -2.06 \\
P4 & -0.12 & 1.27 & -0.02 & 1.85 & -0.03 & 0.73 & $1.32^{*}$ \\
P5 & $0.31^{*}$ & -3.16 & -0.01 & -1.14 & -1.10 & $1.02 *$ & -1.05 \\
P6 & $0.37^{* *}$ & 1.71 & 0.006 & -1.22 & 0.69 & $0.64 * *$ & 0.56 \\
P7 & -0.39 & -2.87 & -0.002 & 1.45 & 1.00 & -1.40 & 1.72 \\
\hline
\end{tabular}

* $p \leq 0.05 ;{ }^{* *} p \leq 0.01 ;$ CMD, Cassava mosaic disease; DMC, Dry matter content; HI, Harvest index; RTN, Storage root number; RTW, storage root weight; TCC, Total carotenoid content; TWT, Total biomass.

In the female parents, $\mathrm{P} 5$ showed a significant positive effect for carotenoid content but high negative effect for dry matter content, although not significant (Table 4). In contrast, parents P3 (IBA061635) and P7 (IBA070536) showed negative GCA effects for carotenoid content. Yellow-fleshed female parents had positive GCA effects for dry matter content. However, P7 (IBA070536) was found to have a negative GCA effect for dry matter content (but not significant). High positive GCA effects for root weight were identified in genotypes P6 (IBA090090) and P7 (IBA070536). 


\subsection{Specific Combining Ability}

Cross $\mathrm{P} 1 \times \mathrm{P} 3$ had positive but non-significant SCA for dry matter content but a negative effect for carotenoid content and RWT (Table 5). Three crosses, P1 $\times$ P6, P2 $\times$ P7 and P1 $\times$ P3, had significant SCA effects for carotenoid content; the first two $(\mathrm{P} 1 \times \mathrm{P} 6$ and $\mathrm{P} 2 \times \mathrm{P} 7)$ crosses had positive values, while the last cross $(\mathrm{P} 1 \times \mathrm{P} 3)$ had a negative (significant) SCA effect for the trait. Four families $(\mathrm{P} 1 \times \mathrm{P} 4, \mathrm{P} 1 \times \mathrm{P} 7, \mathrm{P} 2 \times \mathrm{P} 3$ and $\mathrm{P} 2 \times \mathrm{P} 5)$ showed positive SCA effects for carotenoid content (although not significant). Families $\mathrm{P} 1 \times \mathrm{P} 3$ and P1 $\times$ P6 had significant negative effects for CMD. When SCA means are not significant, the hypothesis is that performance of single cross progeny can be adequately predicted on the basis of the GCA [15].

Table 5. Specific combining ability effects of parents for seven traits evaluated across two locations in Ghana.

\begin{tabular}{cccccccc}
\hline Family & CMD & DMC & HI & RTN & RTW & TCC & TWT \\
\hline P1 $\times$ P3 & $-0.08^{* * *}$ & 4.79 & -0.009 & -1.05 & -0.83 & $-0.26^{* * *}$ & -0.17 \\
P1 $\times$ P4 & 0.07 & $-4.03^{* *}$ & -0.009 & -0.39 & -0.96 & 0.20 & -0.69 \\
P1 $\times$ P5 & 0.01 & 0.71 & $0.008^{* *}$ & 1.79 & $0.70^{* *}$ & -0.17 & $0.61^{* *}$ \\
P1 $\times$ P6 & $-0.06^{* * *}$ & 0.20 & 0.007 & -0.20 & $0.89^{* *}$ & $0.74^{* * *}$ & 0.67 \\
P1 $\times$ P7 & 0.0004 & 0.28 & 0.01 & $0.08^{*}$ & 0.32 & 0.37 & -0.91 \\
P2 $\times$ P3 & 0.06 & $-4.01^{*}$ & 0.01 & $1.14^{*}$ & 0.88 & 0.32 & 0.02 \\
P2 × P4 & -0.09 & 4.81 & 0.01 & 0.48 & $1.01^{*}$ & -0.14 & 0.71 \\
P2 $\times$ P5 & -0.03 & 0.07 & $-0.004^{*}$ & -1.69 & -0.66 & 0.22 & $0.50^{*}$ \\
P2 $\times$ P6 & $0.04^{* *}$ & $0.58^{*}$ & -0.003 & 0.29 & 0.85 & -0.69 & -0.81 \\
P2 $\times$ P7 & $0.02^{* * *}$ & 0.50 & -0.009 & 0.01 & -0.27 & $0.43^{* * *}$ & -0.87
\end{tabular}

${ }^{*} p \leq 0.05 ;{ }^{* *} p \leq 0.01:{ }^{* * *} p \leq 0.001$; CMD, Cassava mosaic disease; DMC, Dry matter content; HI, Harvest index RTN, Storage root number; RTW, storage root weight; TCC, Total carotenoid content; TWT, Total biomass.

When the SCA mean squares are significant, the relative importance of GCA and SCA should be determined by estimating the components of variance to predict the progeny performance [17]. The predictability (or Baker ratio) in this study varied from 0.48 for dry matter content to 0.98 for CMD (Table 3). Most of the studied characteristics had a ratio closer to one for the combined data except for dry matter content, and root weight, indicating the importance of GCA and additive gene effects for most of the characteristics.

\subsection{Phenotypic Correlation}

There was no significant correlation of carotenoid content with harvest index, root weight, root number, or total biomass (yield components) but carotenoid content correlated positive and significant $(p<0.01)$ with pulp color (color intensity) and CMD (Table 6). Positive significant $(p<0.001)$ correlation was recorded for pulp color with CMD. Negative significant correlation were seen between cassava green mite and harvest index; cassava green mite and root weight; CMD and root number; and harvest index and root number. Positive and significant correlation was also seen of CMD with dry matter content. Cortex and pulp color were highly significantly correlated. Harvest index and root number were highly significantly negatively correlated, while root weight and total biomass were highly significantly correlated.

\subsection{Genetic Parameters}

For the combined locations, broad sense heritability ranged from 0.68 (dry matter content) to 0.99 (carotenoid content) and narrow sense heritability from 0.61 (harvest index) to 0.91 (CMD, carotenoid content) (Table 7). Heritability estimates were classified as high $(>0.50)$, medium $(0.30-0.50)$ and low $(<0.30)$ [18]. 
Table 6. Phenotypic correlation of measured cassava characteristics evaluated across two locations.

\begin{tabular}{|c|c|c|c|c|c|c|c|c|c|}
\hline & CGM & CMD & COR & PULP & HI & RTN & RTW & TCC & TWT \\
\hline CMD & 0.17 & & & & & & & & \\
\hline COR & 0.12 & 0.40 & & & & & & & \\
\hline PULP & 0.23 & $0.77^{* * *}$ & $0.58^{* *}$ & & & & & & \\
\hline HI & $-0.50 *$ & 0.18 & 0.14 & 0.28 & & & & & \\
\hline RTN & -0.04 & $-0.45^{*}$ & -0.28 & -0.26 & $-0.51^{*}$ & & & & \\
\hline RTW & $-0.51^{*}$ & -0.23 & -0.20 & -0.03 & 0.38 & 0.49 & & & \\
\hline TCC & -0.02 & $0.55^{* *}$ & 0.34 & $0.59^{* *}$ & 0.01 & -0.05 & 0.23 & & \\
\hline TWT & -0.23 & -0.26 & -0.33 & -0.32 & 0.09 & 0.43 & $0.71^{* * *}$ & 0.29 & \\
\hline DMC & -0.06 & $0.60 * *$ & 0.10 & 0.34 & 0.00 & -0.13 & 0.00 & 0.20 & 0.18 \\
\hline
\end{tabular}

${ }^{*} p \leq 0.05$; ${ }^{* *} p \leq 0.01: * * * \leq 0.001$; CGM, Cassava green mite; CMD, Cassava mosaic disease; COR, Color of the cortex; PULP, Pulp color; HI, Harvest index; RTN, Storage root number; RTW, storage root weight; TCC, Total carotenoid content; TWT, Total biomass; DMC, Dry matter content;.

Table 7. Genetic parameters for various traits studied across two locations in Ghana.

\begin{tabular}{cccccccc}
\hline Characteristic & CMD & DMC & HI & RTN & RWT & TCC & TWT \\
\hline GCAmale & 0.13 & 0.40 & 0.005 & 89.83 & 14.86 & 7.19 & 18.44 \\
GCAfemale & 0.46 & 20.26 & 0.00 & 2.27 & 0.90 & 27.25 & 1.32 \\
SCA & 0.005 & 0.33 & 0.0001 & 4.26 & 1.27 & 1.33 & 1.25 \\
Genotype & 0.21 & 8.57 & 0.0006 & 64.73 & 11.49 & 13.89 & 12.37 \\
Additive & 0.83 & 34.29 & 0.002 & 258.92 & 45.96 & 55.56 & 49.49 \\
Dominance & 0.02 & 1.32 & 0.005 & 17.02 & 5.06 & 5.31 & 4.99 \\
Environmental & 0.07 & 16.91 & 0.001 & 20.28 & 5.37 & 0.22 & 8.21 \\
Heritability (broad) & 0.93 & 0.68 & 0.75 & 0.93 & 0.90 & 0.99 & 0.87 \\
Heritability(narrow) & 0.91 & 0.65 & 0.61 & 0.87 & 0.81 & 0.91 & 0.79 \\
Degree of dominance & 0.16 & 0.20 & 0.5 & 0.26 & 0.33 & 0.31 & 0.32 \\
\hline
\end{tabular}

CMD, Cassava mosaic disease; DMC, Dry matter content; HI, Harvest index; RTN, Storage root number; RTW storage root weight; TCC, Total carotenoid content; TWT, Total biomass.

All the characteristics recorded high heritability, which indicates that selection should be effective using direct recurrent selection.

\section{Discussion}

Mean carotenoid content values in this study varied from 2.98 to $6.14 \mu^{g^{-1}}{ }^{-1}$, with a grand mean of $4.19 \mathrm{\mu g} \mathrm{g}^{-1}$, which is comparable to values reported in Uganda [5,8,19] and in Nigeria [1]. The means, however, were lower than those reported in Colombia [20,21]. The differences observed could be a result of many years of breeding for carotenoid content at CIAT (Colombia), the age of the plant [21], and the nature of the parental lines used in generating the breeding populations. In most of the studies reported in Africa, parental lines were selected solely based on either carotenoid content or dry matter content (whitefleshed), and used in crosses as either male or female parent for each trait, in a design to combine both dry matter content and carotenoid content, to meet stakeholder demands. In other words, a high dry matter content parent crossed to a high carotenoid content parent. Mean dry matter content ranged from 26.86 to $36.28 \%$ with a mean of $30.74 \%$, comparable to values previously reported [5,22], but lower than other reported values [23]. Although the dry matter content grand mean is lower in this study compared to those reported for landraces grown in Ghana by farmers, some individual genotypes had higher dry matter content than that of the commonly grown varieties. These individuals could be selected and further tested towards release, since the trait is one of the key drivers of cassava variety adoption in Ghana. The mean root weight ranged from 14.34 to $18.35 \mathrm{~kg} \mathrm{plot}^{-1}$. These mean values were higher than that of farmer-grown varieties, hence could be adopted by farmers in Ghana, but need to be tested in famers' fields on larger plot sizes. Cassava varieties with high carotenoid content and dry matter content will be rejected by the National Release Committee if they are susceptible to CMD in Ghana. This confirms the 
importance of selecting clones that are resistant or tolerant to CMD. In the current study, all families recorded CMD values less than 2 (resistant) as shown in Table 2.

Some phenotypic correlations in this study are of special importance for selecting high carotenoid content cassava clones in breeding programs. Firstly, the positive significant correlation between pulp color and carotenoid content $[5,9]$, are good for screening large numbers of progenies of elite breeding lines in the cassava breeding program. This is because pulp color is directly impacted by carotenoids, thus is an indicator of vitamin A. carotenoid content and CMD; pulp color and CMD; and pulp color and cortex color were significantly correlated. The correlation between CMD and pulp color (carotenoid content) would need scrutiny to explain the basis underlying this observation. Positive correlation between carotenoid content and CMD was reported [24] when evaluating high $\beta$-carotene cassava genotypes in advanced trials in Nigeria. Most elite parent materials in breeding programs in Africa have been pre-selected for CMD resistance and this explains why the parental materials and progenies showed good CMD resistance. It shows both carotenoid content and CMD could be combined and selected at the early stages by visually assessing the pulp color and CMD symptoms. The reduced number of selected individuals allows for a comfortable size that could be subjected to more demanding quantitative screening analysis for carotenoid content in the later stages of the program to save cost. Beta-carotene (carotenoid content in our case) can be measured quantitatively through a color chart (visual assessment) estimate since its field estimates (based on the chart carotenoid content values) significantly correlated with those from the laboratory analysis (quantification) in sweet potatoes [25]. The low positive correlation (not significant) between carotenoid content and dry matter content may not be very useful for developing cassava varieties that combine both characteristics. Negative correlations between carotenoid content and dry matter content in both cassava and sweet potatoes were reported [5,25].

An initial negative association between dry matter content and carotenoid content in CIAT cassava germplasm was seen [21], which turned into a positive association after years of recombination and selection. Hence, several years of recombination and selection could help cassava breeders combine both characteristics in African breeding programs.

A negative correlation was observed between CMD and the yield components (root number, total biomass and root weight), which is due to the fact that CMD severity is scored low for high resistance and vice versa. So good disease response (low scores) go with high yield response (including yield components). This implies, therefore, that yield and yield components respond positively to selection for resistance to pests and diseases. This is the result of the negative impact of diseases and pests on cassava root yield [1,26-28]. The positive significant correlation between root number and root weight, and total biomass and RWT, has also been reported by several other authors [7,28-30]. This indicates that the higher the root number, the higher the root weight, and eventually the root yield. The non-significant correlation between RWT and dry matter content suggested that there was no pleiotropic effect between them, and that they can be selected for independently. However, there is a need for breeding to combine both characteristics to enhance dry root yield which is critical to the commercialization of the crop. Recombination and selection will therefore need to be corrected through crosses and then selected for at early stages of a breeding program. Combined yield and dry matter content selection should therefore be possible at the seedling stage [22]. Lastly, the negative correlation between pulp color and root number and root weight has also been reported in [31], which stated that color is highly correlated with $\beta$-carotene and negatively with RWT, which is a key driver for adoption. This means that improving the color may compromise the root yield. Again, simultaneous selection for both characteristics into a single genotype should be a breeding objective and should be carried out for both root color and yield for value addition to the crop.

Genetic information was generated in the current study in order to estimate GCA and SCA values for characteristics of interest. The proportion sum of squares of both GCA and SCA as percentage of total sum of squares were calculated to help determine the relative 
importance of additive and non-additive effects [32]. This information is critical in the selection of appropriate progenitors and breeding methods for efficient cassava breeding for CMD, dry matter content and carotenoid content. GCA sum of squares were higher than their respective SCA sum of squares for CMD, harvest index and carotenoid content, explaining more than $70 \%$ of the total variation. This suggests that additive gene effects are more important for the three characteristics. GCA accounted for a significantly larger proportion of sum of squares than SCA for harvest index and carotenoid content [5]. Larger GCA than SCA sum of squares were reported in sweet potatoes for $\beta$-carotene [33]. Larger GCA than SCA sum of squares for CMD severity and harvest index were also reported [31]. The relative importance of additive gene action for carotenoid content, CMD and harvest index was confirmed by high Baker ratios (more than 0.5) for these characteristics. The results suggest that both carotenoid content and CMD could be enhanced through recurrent mass selection due to the additive nature and high heritability for these characteristics [21].

Improved varieties released in the 1980s and 1990s by IITA explored additive genetic effects for CMD resistance. The discovery of a dominant CMD2 gene [34] has since facilitated the rapid development of CMD resistance in cassava, and breeding programs in Africa have explored this gene in the development of most varieties released in the 2000s and subsequently. The use of both additive and dominance genetic variance could enhance the development of more durable and stable CMD resistance genetic backgrounds for the introgression of other characteristics such as carotenoid content and dry matter content. Further studies need to be carried out on the parental lines used in this study to ascertain whether any of the parental lines have the CMD2 gene.

It might be difficult to combine dry matter content and carotenoid content due to the larger SCA sum of squares for the former, an indication of non-additive effects. Dry matter content is under the influence of non-genetic effects [22,23]. However, the presence of some yellow-fleshed genotypes that have dry matter content values in the same range as the white-fleshed progenitors is an indication that it is possible to breed for both carotenoid content and dry matter content. However, larger dry matter content SCA than GCA sum of squares (67.9\%) was reported [29], indicating the influence of non-additive gene action.

GCA and SCA mean squares were significant for root number and root weight, which implies that these characteristics showed significant additive and dominance genetic variances, contrasting to what was reported [25]. GCA sum of squares were larger than their respective SCA sum of squares for root number and RWT, suggesting the predominance of additive genetic effects, as also reflected in their mean squares. Progenitor P6 (IBA090090) showed positive GCA effects for carotenoid content, dry matter content, root weight and $\mathrm{CMD}$, hence could be crossed to a genetic background of high dry matter content to increase chances of generating clones that combine both carotenoid content and dry matter content.

Narrow sense heritability for the characteristics were high in general. High broadsense heritability for number of storage roots was reported in different studies [28,35]. Broad sense heritability was generally higher than narrow sense heritability for all characteristics. High heritability of a characteristic can be exploited by plant breeders through selection [7]. Narrow sense heritability is more important, as it measures the relative importance of the additive portion of the genetic variance that can be transmitted to the next generation of the offspring [36]. Hence, the high narrow sense heritability observed for all the characteristics were good for the breeding program.

\section{Conclusions}

Data generated from this study can be applied for planning an efficient cassava breeding strategy for developing yellow-fleshed cassava in Ghana. GCA effects were larger than SCA effects for CMD, harvest index and carotenoid content with a predictability ratio close to 1 , indicating the presence of additive gene effects and a possibility for improvement of the characters by selection. Some yellow-fleshed genotypes with dry matter content values in the same range as the white-fleshed progenitors is an indication that it is possible to breed for both carotenoid content and dry matter content in breeding programs in Africa, 
and this was confirmed by the positive (though not significant) correlation between the two characteristics. Progenitor P6 (IBA090090) showed positive GCA effects for carotenoid content, dry matter content, root weight and CMD, hence could be crossed to a high dry matter content background to increase chances of generating clones that combine carotenoid content and dry matter content. Findings of this study showed that yield and quality characteristics can be selected simultaneously, such as dry matter content, in early stages of the breeding cycle.

Author Contributions: Conceptualization, E.Y.P., B.B.P.; methodology, E.Y.P., B.B.P., P.K.; investigation, B.B.P.; supervision, M.T.L., A.v.B., E.Y.P. All authors have read and agreed to the published version of the manuscript.

Funding: This research was funded by the Bill and Melinda Gates Foundation (BMGF) (Grant No. OPP1112552) and HarvestPlus (IITA).

Data Availability Statement: Data is available from the corresponding author.

Acknowledgments: The authors are grateful to Elizabeth Afriyie Duah, Peter Illuebey, CSIR-CRI outstations, and the Cassava Breeding Unit, IITA-Nigeria, for providing the yellow-fleshed genotypes used in this study.

Conflicts of Interest: The authors declare no conflict of interest.

\section{References}

1. Ssemakula, G.; Dixon, A. Genotype x environment interaction, stability and agronomic performance of carotenoid-Rich cassava clones. Sci. Res. Essay 2007, 2, 390-399.

2. Bouis, H.E.; Hotz, C.; McClafferty, B.; Meenakshi, J.V.; Pfeiffer, W.H. Biofortification: A new tool to reduce micronutrient malnutrition. Food Nutr. Bull. 2011, 32, S31-S40. [CrossRef] [PubMed]

3. Dwivedi, S.L.; Sahrawat, K.L.; Rai, K.N.; Blair, M.W.; Andersson, M.S.; Pfeiffer, W. Nutritionally enhanced staple food crops. Plant Breed. Rev. 2012, 36, 173-293.

4. Nassar, N.M.A.; Ortiz, R. Breeding cassava to feed the poor. Sci. Am. 2010, 302, 78-82. [CrossRef]

5. Esuma, W.; Kawuki, R.S.; Herselman, L.; Labuschagne, M.T. Diallel analysis of provitamin A carotenoid and dry matter content in cassava (Manihot esculenta Crantz). Breed Sci. 2016, 66, 627-635. [CrossRef]

6. Njoku, D.W. Improving Beta-Carotene Content in Farmers' Preferred Cassava Cultivars in Nigeria. Ph.D Thesis, WACCI, University of Ghana, Legon, Ghana, 2012.

7. Akinwale, M.G.; Aladesanwa, R.D.; Akinyele, B.O.; Dixon, A.G.O.; Odiyi, A.C. Inheritance of $\beta$-carotene in cassava (Manihot esculenta Crantz). Int. J. Gen. Mol. Biol. 2010, 2, 198-201.

8. Njoku, D.N.; Gracen, V.E.; Offei, S.K.; Asante, I.K.; Egesi, C.N.; Kulakow, P.; Ceballos, H. Parent offspring regression analysis for total carotenoids and some agronomic traits in cassava. Euphytica 2015, 206, 657-666. [CrossRef]

9. Chávez, A.L.; Sánchez, T.; Jaramillo, G.; Bedoya, J.M.I.; Echeverry, J.; Bolaños, E.A.; Ceballos, H.; Iglesias, C.A. Variation of quality traits in cassava roots evaluated in landraces and improved clones. Euphytica 2005, 143, 125-133. [CrossRef]

10. Sánchez, T.; Ceballos, H.; Dufour, D.; Ortiz, D.; Morante, N.; Calle, F.; Zum Felde, T.; Dominguez, M.; Davrieux, F. Prediction of carotenoids, cyanide and dry matter contents in fresh cassava root using NIRS and hunter color techniques. Food Chem. 2014, 151, 444-451. [CrossRef] [PubMed]

11. IITA (International Institute of Tropical Agriculture). Cassava in Tropical Africa: A Reference Manual; IITA: Wisbech, UK, 1990.

12. Centro Internacional de Agricultura Tropical (CIAT). Improved Cassava for the Developing World: Annual Report; CIAT: Cali, Colombia, 2003.

13. Kawano, K.; Narintaraporn, K.; Narintaraporn, P.; Sarakarn, S.; Limsila, A.; Limsila, J.; Suparhan, D.; Sarawat, V.; Watananonta, W. Yield improvement in a multistage breeding program for cassava. Crop Sci. 1998, 38, 325-332. [CrossRef]

14. Rodriguez, F.; Gregorio, A.; Pacheco, A.; Crossa, J.; Burgueno, J. Analysis of Genetic Designs with R (AGD-R), Version 5.0. CIMMYT Research Software; CIMMYT: Texcoco, Mexico, 2015.

15. Baker, R.J. Issues in diallel analysis. Crop Sci. 1978, 18, 533-536. [CrossRef]

16. Hirut, B.; Shimelis, H.; Fentahun, M.; Bonierbale, M.; Gastelo, M.; Asfaw, A. Combining ability of highland tropic adapted potato for tuber yield and yield components under drought. PLoS ONE 2017, 12, e0181541. [CrossRef]

17. Fasahat, P.; Rajabi, A.; Rad, J.M.; Derera, J. Principles and utilization of combining ability in plant breeding. Biom. Biostat. Int. J. 2016, 4, 1-22. [CrossRef]

18. Bhateria, S.; Sood, S.P.; Panthania, A. Genetic analysis of quantitative traits across environments in linseed (Linum usitatissimum L.). Euphytica 2006, 150, 185-194. [CrossRef]

19. Maroya, N.G.; Kulakow, P.; Dixon, A.G.O.; Maziya-Dixon, B.B. Genotype x environment interaction of mosaic disease, root yields and total carotene concentration of yellow-fleshed cassava in Nigeria. Int. J. Agron. 2012, 2012, 434675. [CrossRef] 
20. Ortiz, D.; Sánchez, T.; Morante, N.; Ceballos, H.; Pachon, H.; Duque, M.C.; Chavez, A.L.; Escobar, A.F. Sampling strategies for proper quantification of carotenoid content in cassava breeding. J. Plant Breed. Crop Sci. 2011, 3, 14-23.

21. Ceballos, H.; Morant, N.; Sanchez, T.; Ortiz, D.; Aragon, I.; Chavez, A.L.; Pizarro, M.; Calle, F.; Dufour, D. Rapid cycling recurrent selection for increased carotenoids content in cassava roots. Crop Sci. 2013, 53, 2342-2351. [CrossRef]

22. Tumuhimbise, R.; Shanahan, P.; Melis, R.; Kawuki, R.S. Combining ability analysis of storage root yield and related traits in cassava at the seedling evaluation stage of breeding. J. Crop Impr. 2014, 28, 530-540. [CrossRef]

23. Kamau, J.; Melis, R.; Laing, M.; Derera, J.; Shanahan, P.; Ngugi, E. Combining the yield ability and secondary traits of selected cassava genotypes in the semi-arid areas of Eastern Kenya. J. Plant Breed. Crop Sci. 2010, 2, 181-191.

24. Edoh, N.L.; Adiele, J.; Ndukwe, I.; Ogbokiri, H.; Njoku, D.N.; Egesi, C.N. Evaluation of high beta carotene cassava genotypes at advanced trial in Nigeria. Open Conf. Proc. J. 2015, 7, 144-148. [CrossRef]

25. Mbusa, H.K.; Ngugi, K.; Florence, M.O.; Kivuva, B.M.; Muthoni, J.W.; Nzuve, F.M. The inheritance of yield components and beta carotene content in sweet potato. J. Agr. Sci. 2018, 10, 71-81. [CrossRef]

26. Hahn, S.K.; Terry, E.R.; Leuschner, K. Breeding cassava for resistance to cassava mosaic disease. Euphytica 1980, $29,673-683$. [CrossRef]

27. Fokunang, C.; Ikotun, T.; Dixon, A.; Akem, C. Field reaction of cassava genotypes to anthracnose, bacterial blight, cassava mosaic disease and their effects on yield. Afr. Crop Sci. J. 2000, 8, 179-186. [CrossRef]

28. Parkes, E.Y.; Fregene, M.; Dixon, A.G.O.; Peprah, B.B.; Labuschagne, M.T. Combining ability of cassava genotypes for cassava mosaic disease and cassava bacterial blight, yield and its related components in two ecological zones in Ghana. Euphytica 2013, 194, 13-24. [CrossRef]

29. Ntawuruhunga, P.; Dixon, A.G.O. Quantitative variation and interrelationship between factors influencing cassava yield. J. Appl. Biosci. 2010, 26, 1594-1602.

30. Chikoti, C.P.; Shanahan, P.; Melis, R. Combining ability analysis of cassava (Manihot esculenta Crantz) genotypes for cassava mosaic disease in Zambia. Austr. J. Crop Sci. 2016, 10, 956-963. [CrossRef]

31. Ojulong, H.F. Quantitative and Molecular Analysis of Agronomic Traits in Cassava (Manihot Esculenta Crantz). Ph.D Thesis, University of the Free State, Bloemfontein, South Africa, 2006.

32. Falconer, D.S.; Mackay, T.F.C. Introduction to Quantitative Genetics, 4th ed.; Longman Scientific and Technical Co.: Essex, UK, 1996.

33. Baafi, E.; Ofori, K.; Carey, E.E.; Gracen, E.V.; Blay, E.T.; Manu-Aduening, J. Genetic control of beta-carotene, iron and zinc content in sweetpotato. J. Plant Studies 2016, 6, 1-10. [CrossRef]

34. Akano, A.; Dixon, A.; Mba, C.; Barrera, E.; Fregene, M. Genetic mapping of a dominant gene conferring resistance to cassava mosaic disease. Theor. Appl. Genet. 2002, 105, 521-525. [CrossRef] [PubMed]

35. Shumbusha, D.; Tusiime, G.; Edema, R.; Gibson, P.; Adipala, E.; Mwanga, R.O.M. Inheritance of root dry matter content in sweetpotato. Afr. Crop Sci. J. 2014, 22, 69-78.

36. Fehr, W.R. Principles of Cultivar Development (Vol. 1): Theory and Technique; Macmillan Publishing Company: New York, NY, USA, 1991. 